\title{
Extinction Limits of Catalytic Combustion in Microchannels
}

\author{
Kaoru Maruta, Koichi Takeda \\ Faculty of Systems Science and Technology, Akita Prefectural University \\ 84-4 Tsuchiya-Ebinokuchi, Honjyo, Akita 015-0055, Japan \\ Jeongmin Ahn, Kevin Borer, Lars Sitzki, Paul D. Ronney \\ Dept. of Aerospace and Mechanical Engineering, University of Southern California \\ Los Angeles, CA 90089-1453 USA \\ Olaf Deutschmann \\ Interdisciplinary Center for Scientific Computing (IWR), University of Heidelberg \\ D-69120 Heidelberg Germany
}

Corresponding author:

Prof. Kaoru MARUTA

Akita Prefectural University

84-4 Tsuchiya-Ebinokuchi, Honjyo, Akita 015-0055, Japan

Phone: 81-184-27-2128

Fax: 81-184-27-2188

E-mail: k_maruta@akita-pu.ac.jp

Word count:

Text including references: $\quad=3230$ words (counted by Microsoft Word 2001)

Figures: $8 \quad=2400$ words (Figure 2, 5, 6, 7 count as 400 words each)

Total: $\quad=\mathbf{5 6 3 0}$ words

Colloquium topic: 14. New Concepts in Combustion Technology

To appear in the Proceedings of the Combustion Institute, Vol. 29. 


\title{
Extinction Limits of Catalytic Combustion in Micro-channels
}

\author{
Kaoru MARUTA ${ }^{1}$, Koichi Takeda ${ }^{1}$, Jeongmin $\mathrm{Ahn}^{2}$, Kevin Borer ${ }^{2}$, Lars Sitzki ${ }^{2}$, Paul D. \\ Ronney $^{2}$ and Olaf Deutschmann ${ }^{3}$ \\ ${ }^{1}$ Akita Prefectural University, Japan \\ ${ }^{2}$ University of Southern California, USA \\ ${ }^{3}$ University of Heidelberg, Germany
}

\begin{abstract}
The limits to self-sustaining catalytic combustion in a micro-scale channel was studied computationally using a cylindrical tube reactor. The tube, $1 \mathrm{~mm}$ in diameter, $10 \mathrm{~mm}$ long and coated with Pt catalyst, was assumed to be thermally thin and the boundary condition on the wall was set to be either adiabatic or non-adiabatic with fixed heat transfer coefficient. Methane-air mixtures with average velocities of 0.0375 to $0.96 \mathrm{~m} / \mathrm{s}$ (corresponding to Reynolds number, Re, ranging from 2.5 to 60 ) were used. When the wall boundary condition was adiabatic, the equivalence ratio at the extinction limit monotonically decreased with increasing $R e$. In contrast, for non-adiabatic conditions the extinction curve exhibited U-shaped dual limit behavior, that is, the extinction limits increased/decreased with decreasing $R e$ in smaller/larger $R e$ regions, respectively. The former extinction limit is caused by heat loss through the wall and the latter is a blow-off type extinction due to insufficient residence time compared to chemical time scale. These heat-loss type and blow-off type extinction limits are characterized by small/large surface coverage of $\mathrm{Pt}(\mathrm{s})$, and conversely large/small numbers of surface coverage of $\mathrm{O}(\mathrm{s})$. It was found that by diluting the mixture with $\mathrm{N}_{2}$ rather than air, the fuel concentration and peak temperatures at the limit decreased substantially for mixtures with fuel to oxygen ratios even slightly rich of stoichiometric due to a transition from $\mathrm{O}(\mathrm{s})$ coverage to $\mathrm{CO}(\mathrm{s})$ coverage. Analogous behavior was observed experimentally in a heat-recirculating "Swiss roll" burner at low Re, suggesting that the phenomenon is commonplace in catalytic combustors near extinction. No corresponding behavior was found for non-catalytic combustion. These results suggest that exhaust gas recirculation rather than lean mixtures are preferable for minimizing flame temperatures in catalytic micro-combustors.
\end{abstract}




\section{Introduction}

With the progress of research and development in MEMS (Micro Electro-Mechanical Systems), much smaller and higher energy density electrical power sources are required. One possible solution for this might be the development of micro-combustors $[1,2,3]$ because hydrocarbon energy densities are approximately 100 times higher than the state-of-the-art lithium-ion batteries. If microcombustors were successfully developed and combined with appropriate energy conversion devices to utilize this advantage, lighter and/or longer lifetime electrical power sources could be realized.

Development of micro-scale combustors, however, faces various technical difficulties, especially heat losses. As devices are scaled down, their surface area to volume ratio becomes larger. This results in larger heat loss rate (which scales with surface area) relative to heat generation rate (which scales with volume) in the system, which causes flame quenching. To overcome this difficulty and establish stable heat generation in micro-scale combustors, thermal management $[4,5]$ and/or catalytic reaction [6] may be required. In catalytic reaction, because the chemical reactions only occur at the catalyst surface, the location of the heat source is fixed. Hence, combustor heat transfer design is simpler than with gas-phase combustion in which the reaction zone location may change in undesirable ways. Also, generally catalytic combustion can be sustained at lower temperature than gas-phase combustion, which reduces heat loss and thermal stress problems. Furthermore, in micro-combustors the higher surface area to volume ratio increases the flux of reactants to the catalyst surface, which could help overcome the larger heat losses and make catalytic combustion even more attractive.

Since catalysts have been extensively used for purposes of, for instance, reducing toxic components in automobile exhaust gas, reforming processes in chemical plants and first-stage combustion in multi-staged gas turbines, numerous studies on catalytic reactions have been conducted and detailed modeling of surface reaction has been successfully conducted [7, 8]. However, since stable stand-alone thermal power generation by hydrocarbon-fueled catalytic reaction is not a major application of catalysts, relatively few studies have been conducted in

this context, particularly at micro-scales. Recently, some researchers [9, 10] have attempted to employ catalytic combustion in micro-scale power generator. Since these works emphasized making prototypes of MEMS power generators, the details of catalytic combustion at 
microscales was not examined. Recently Sitzki et al. [11] experimentally investigated the extinction characteristics of Swiss-roll type heat-recirculating catalytic burners and reported two types of extinction limits, a heat loss induced limit at low Reynolds numbers $(R e)$ characteristic of micro-combustors and a blow-off type limit at higher Re. Also Maruta et al. [12] conducted an initial modeling study of catalytic combustion relevant to micro-combustors. To the authors' knowledge, however, the general operating characteristics of micro-scale catalytic combustion such as extinction limits have not yet been determined. We consider extinction limits to be perhaps the most important issue for micro-scale catalytic combustion because of the aforementioned scaling considerations.

In the present study, the extinction limits for self-sustaining catalytic combustion in micro-scale channels, is examined computationally. For simplicity a cylindrical tube reactor whose inner wall is coated with platinum is employed. We employ methane as a model fuel since it is the simplest hydrocarbon and the only hydrocarbon for which reliable detailed surface reaction mechanisms are available.

\section{Computational methods}

The micro-scale flow reactor channel was a cylindrical tube of $1 \mathrm{~mm}$ diameter and 10 $\mathrm{mm}$ length. Methane-air mixtures of equivalence ratios from stoichiometric to the extinction limit were supplied to the channel at averaged inlet velocities from 0.0375 to $0.96 \mathrm{~m} / \mathrm{s}$, corresponding to inlet Reynolds numbers from 2.5 to 60 . To avoid numerical complications associated with the catalyst leading edge coinciding with the inlet boundary conditions, as in [13] the first $1 \mathrm{~mm}$ length of channel was assumed to be an inert wall. The remaining $9 \mathrm{~mm}$ of the channel was assumed to be platinum catalyst. The channel wall is assumed to be thermally thin so that axial heat conduction along the wall is neglected. Of course, in general axial conduction (and radiation) may be significant and will be considered in future investigations.

The channel diameter of $1 \mathrm{~mm}$ was chosen because this size is smaller than the quenching diameter of gas-phase methane-air combustion and because it is comparable to sizes proposed in many micro-scale combustor designs. Also, at this scale gas-phase reactions can be neglected. Ohadi and Buckley [14] modeled stoichiometric methane-air mixtures reacting in

tubes with heat loss coefficient $\mathrm{H}=0.26 \mathrm{~W} / \mathrm{m}^{2} \mathrm{~K}$ (which is much smaller than we employ) and 
found that no stable gas-phase reaction could be sustained in tube diameters less than $2.25 \mathrm{~mm}$, even for residence times up to 1 second (which is much longer than our residence times). They also showed that if quenching of radicals at the tube wall is considered, the critical tube diameter increases to $3.5 \mathrm{~mm}$.

The two-dimensional, axisymmetric Navier-Stokes equations were solved using the FLUENT commercial fluid dynamics code [15] coupled to external subroutines [16] to model surface reaction at the channel walls. The subroutines calculate the mass fluxes at the wall due to the surface reactions and the surface coverage with chemical species adsorbed by the walls. The governing equations and surface reactions are the same as those used by Deutschmann et al. [17]. The surface reaction mechanism [18] consists of 24 heterogeneous reactions involving eleven surface species ( $\mathrm{Pt}(\mathrm{s}), \mathrm{CH}_{3}(\mathrm{~s}), \mathrm{CH}_{2}(\mathrm{~s}), \mathrm{CH}(\mathrm{s}), \mathrm{C}(\mathrm{s}), \mathrm{CO}(\mathrm{s}), \mathrm{CO}_{2}(\mathrm{~s}), \mathrm{H}_{2} \mathrm{O}(\mathrm{s}), \mathrm{OH}(\mathrm{s}), \mathrm{H}(\mathrm{s})$ and $\mathrm{O}(\mathrm{s}))$ and seven gaseous species $\left(\mathrm{CH}_{4}, \mathrm{O}_{2}, \mathrm{~N}_{2}, \mathrm{H}_{2} \mathrm{O}, \mathrm{CO}_{2}, \mathrm{CO}\right.$ and $\left.\mathrm{H}_{2}\right)$. Gas-phase reaction is not modeled for the reason stated above. Wall boundary conditions corresponding to heat transfer coefficients $\mathrm{H}=5$ or $10 \mathrm{~W} / \mathrm{m}^{2}-\mathrm{K}$ were applied. These values are representative of well-insulated tubes in which $\mathrm{H} \sim \mathrm{k} / \mathrm{d}$, where $\mathrm{k}$ is the thermal conductivity of air $(0.026 \mathrm{~W} / \mathrm{m}-\mathrm{K})$ (or air-filled insulators such as aerogels) and $d$ is the tube diameter $(0.001 \mathrm{~m})$. Computations were also performed with adiabatic walls for comparison purposes only; if the wall is adiabatic, temperatures are much higher and gas-phase reaction cannot be neglected.

With this scheme we tried to elucidate the operating characteristics of self-sustaining micro-combustors in which the heat release due to surface reaction and heat loss to the environment determine the actual temperature profiles, as opposed to many catalytic combustion studies in which wall temperatures are artificially imposed. For the first computation, wall temperatures sufficiently high enough for initiation of surface reaction are used as an ignition source. Once a steady solution is obtained, subsequent calculations are made without prescribed wall temperatures using the previous result as the starting estimate for the next solution.

\section{Results and Discussion}

\section{Extinction limit boundaries}

Figure 1 shows the computed equivalence ratios at the extinction limit as a function of the averaged mixture inlet velocity. Above the extinction limit concentration catalytic reaction is 
self-sustaining. When heat losses exist, the extinction curves exhibit U-shaped dual limit behavior. These limits are analogous to the extinction characteristics often found for ordinary gas-phase combustion, for example on porous-plug flat-flame burners that have both blow-off and heat loss type extinction limits at higher and lower velocities, respectively. For adiabatic conditions, the heat loss extinction limit at lower velocity disappears, the equivalence ratio at the extinction limit increases monotonically with increasing mixture velocity and the maximum temperature in the channel is close to the mixture adiabatic flame temperature. For $\mathrm{H}=5$ and $10 \mathrm{~W} / \mathrm{m}^{2}-\mathrm{K}$, maximum temperatures are 100-200 K lower than adiabatic. The marked points $a$, $b$ and $c$ will be used for later discussion of the two kinds of extinction limits.

Total heat release, total heat loss through the channel wall and ratios of these are shown in Fig. 2. Note that these values correspond to those at the extinction limits, not at constant equivalence ratio. Figure 2 (upper) shows that the total heat release increases with increasing mixture velocity simply due to the greater flux of reactants as velocity increases. The total heat loss also increases with the averaged mixture velocities (Fig. 2, middle) but saturates at high velocity because the limit temperatures (not shown) approach a nearly constant value as velocity increases. Figure 2 (lower) shows that when heat losses exist, the ratio of total heat loss to total heat release increases as velocity decreases, even though the maximum temperature is lower, because the residence time is longer at lower velocity. At sufficiently low velocity almost all the heat released by reaction is lost through the wall, emphasizing the importance of heat loss on the lower velocity extinction limit.

\section{Mechanisms of extinction limits}

For detailed discussion of the two kinds of extinction mechanisms, we choose two points $a$ and $b$ on the extinction limit curve for $\mathrm{H}=10 \mathrm{~W} / \mathrm{m}^{2} \mathrm{~K}$ (Fig. 1) and for reference, point $c$ on the adiabatic curve. The equivalence ratio is 0.8 for both points $a$ and $b$. The averaged mixture velocity for points $b$ and $c$ is $0.48 \mathrm{~m} / \mathrm{s}$, and for point $a$ is $0.065 \mathrm{~m} / \mathrm{s}$. Figure 3 shows the axial wall temperature profiles for these three cases. For point $c$, the adiabatic high-velocity case, the temperature starts to increase close to the leading edge of the catalytic surface and rises to nearly the adiabatic flame temperature of this mixture. Since the boundary is adiabatic, the wall temperature stays constant all the way to the channel exit. For cases $a$ and $b$, wall temperatures decrease downstream due to heat losses through the wall. Because residence times are longer at 
lower mixture velocities, the peak temperature is much lower for case $a$ and the wall temperature downstream of the reaction zone decreases almost to ambient. This difference in temperature distributions for cases $a$ and $b$ plays a significant role on the mechanism of extinction limits discussed below. Note also that for case $a$ the temperature starts to rise even before the beginning of the catalyst wall. This is due to axial diffusion of heat that is only important at lower $\operatorname{Re}(=4.3$ for case $a)$.

To examine how surface reaction occurs on the catalytic wall, axial profiles of $\mathrm{CH}_{4}$ mole fraction in gas phase next to the wall and heat release per unit length on the wall are plotted in Fig. 4 for cases $a$ and $b$. Although the profiles are quantitatively different, no significant qualitative difference exists except for the larger effect of axial $\mathrm{CH}_{4}$ diffusion for case $a$. For both cases heat release is observed close to the leading edge of the catalytic wall and almost all fuel is consumed in this region. Note in case $a$ there is a small but constant amount of unreacted $\mathrm{CH}_{4}$ downstream of the reaction. Chemical reaction is frozen in this region because the temperature very low (Fig. 3). For case $b$ the $\mathrm{CH}_{4}$ mole fraction at the channel exit is at least 10,000 times lower because the downstream temperature is high enough to allow reaction to proceed.

To examine this qualitative difference between cases $a$ and $b$, the surface coverage (the fraction of surface sites covered by a particular species) is plotted in Fig. 5. For case $a, \operatorname{Pt}(\mathrm{s})$ surface coverage peaks at the region of significant reaction, then decreases rapidly downstream of this region. $\mathrm{O}(\mathrm{s})$ surface coverage changes inversely such that almost all sites are occupied by either $\mathrm{Pt}(\mathrm{s})$ or $\mathrm{O}(\mathrm{s})$. Among other surface species $\mathrm{OH}(\mathrm{s})$ occupies the largest fraction (of the order $10^{-3}$ ); other species were at least two orders of magnitude lower still. Note that the peak of $\mathrm{Pt}(\mathrm{s})$ surface coverage and minimum of $\mathrm{O}(\mathrm{s})$ coverage coincide with peak of wall temperature and heat release. Consequently, the potential reactivity of catalyst can be characterized by sufficiently high temperature and large $\mathrm{Pt}(\mathrm{s}) / \mathrm{O}(\mathrm{s})$ ratio. As described in [18], larger $\mathrm{O}(\mathrm{s})$ surface coverage inhibits adsorption of methane by the surface at low temperature. With increasing surface temperature the adsorption-desorption equilibrium shifts towards desorption, leading to increased $\mathrm{Pt}(\mathrm{s})$, which in turn results in increased $\mathrm{CH}_{4}$ adsorption. In case $b$, the behavior of the $\mathrm{Pt}(\mathrm{s})$ and $\mathrm{O}(\mathrm{s})$ profiles are somewhat similar to case $a$, though because in case $b$ the temperatures are higher and remain higher for a larger downstream 
distance, $\operatorname{Pt}(\mathrm{s})$ is much higher and remains higher further downstream. This allows almost all $\mathrm{CH}_{4}$ that leaks downstream of the main reaction zone to be oxidized before exiting the tube.

\section{Effects of nitrogen dilution on extinction limits at constant equivalence ratio}

The results for lean methane-air mixtures shows that a minimum temperature of about $1300 \mathrm{~K}$ is needed to sustain catalytic combustion. This rather high temperature may cause severe materials limitations and substantial thermal stresses in micro-combustors. In this section we identify a better means of obtaining self-sustaining catalytic micro-combustion at low temperatures than by merely using leaner mixtures. A set of computations was performed in which the fuel/oxygen ratio was held fixed and the mixtures were diluted with nitrogen until the extinction limit was reached. This is different from fuel-air mixtures where the oxygen/nitrogen ratio is fixed. Of course $\mathrm{N}_{2}$ dilution is not a practical operating strategy, but it is representative of dilution with exhaust gases, which is potentially practical. An operating condition representative of non-adiabatic micro-combustors (velocity $0.06 \mathrm{~m} / \mathrm{s}, \mathrm{H}=5 \mathrm{~W} / \mathrm{m}^{2} \mathrm{~K}$ ) was chosen for these calculations. Figure 6 shows the predicted extinction limits. It is remarkable that for mixtures even slightly rich of stoichiometric (fuel/oxygen $=0.5$ ), the

minimum fuel concentration and peak temperature required to support self-sustaining catalytic combustion drops by almost half. Figure 7 shows the surface coverage profiles for the limit cases. The stoichiometric case shows behavior qualitatively similar to lean limits where $\operatorname{Pt}(\mathrm{s})$ increases and $\mathrm{O}(\mathrm{s})$ decreases in the reaction zone although $\mathrm{O}(\mathrm{s})$ stays low for some distance downstream since there is no excess oxygen in the gas phase. For the slightly rich case, $\operatorname{Pt}(\mathrm{s})$ at the leading edge of the catalyst region is nearly twice as high and the coverage species $\mathrm{CO}(\mathrm{s})$ rather than $\mathrm{O}(\mathrm{s})$ since the mixture is slightly oxygen-deficient overall. $\mathrm{CO}(\mathrm{s})$ is far less effective than $\mathrm{O}(\mathrm{s})$ at suppressing $\mathrm{CH}_{4}$ adsorption [18] and allows combustion to proceed at much lower temperatures than stoichiometric and lean mixtures do.

\section{Experiments}

To examine whether the computed behavior of extinction limits for varying fuel/oxygen ratios applies to real combustors, experiments were conducted using a 3-turn inconel "Swiss roll" combustor, $6.5 \mathrm{~cm}$ tall and having $0.39 \mathrm{~cm}$ wide channels. The temperature in each inlet and 
outlet turn is measured with chromel-alumel thermocouples. About $31 \mathrm{~cm}^{2}$ of bulk Pt sheet, cut into strips $1 \mathrm{~cm}$ wide, was placed in the center of the burner. Other details of the experimental apparatus are described elsewhere [11]. Tests were performed with $\operatorname{Re}=4$ based on the width, gas velocity and viscosity in the catalytic section of the burner. This value of $R e$ is similar to that employed in the calculations leading to Fig. 6.

It was not possible to use methane in these experiments because the temperatures required to sustain combustion on the lean-side of stoichiometric was beyond the limits of the burner. Consequently, propane was used instead. Of course, a Swiss-roll burner operating on propane is different from a straight tube combustor using methane, but it is of interest to determine whether the computed results are specific to the modeled geometry and fuel or more general.

Figure 8 shows the measured extinction limits and peak temperatures with and without catalyst. The observed decrease in limit propane mole fraction (from $1.87 \%$ to $1.32 \%$ ) as the stoichiometric fuel/oxygen ratio is crossed is somewhat less than that computed for methane but still very substantial. The decrease in limit temperature is also seen although it is much less substantial than the computed decrease. No similar behavior is found when the catalyst is removed - rich of stoichiometric, the reactants are oxygen-deficient and increasing the fuel/oxygen ratio leads to a higher limit fuel concentration in order to provide sufficient oxygen. Note also that for lean mixtures the limiting fuel concentration with catalyst is actually higher than that without catalyst. This was also seen in our previous experiments using a ceramic Swiss-roll burner [2] with the same catalyst material. Thermocouple data show that for lean mixtures with catalytic combustion, the peak temperature (thus, presumably, the chemical reaction) occurs not at the center of the burner where the catalyst is but rather one turn outside the burner center on the inlet side. Thus, for our conditions the catalyst actually tends to suppress combustion (perhaps by adsorbing radicals) for lean but not rich mixtures.

\section{Conclusions}

Extinction limits of self-sustaining methane-fueled combustion on Pt catalyst in non-adiabatic micro-scale flow reactor channels were studied computationally. Results showed that catalytic combustion exhibited U-shaped dual extinction limits, one being a high-velocity blow-off 
(insufficient residence time) limit and the other a low-velocity heat loss induced extinction limit. These two limits are characterized, respectively, by large/small Pt(s) and small/large $\mathrm{O}(\mathrm{s})$ surface coverage. By diluting the mixture with $\mathrm{N}_{2}$ rather than air, the fuel concentration and peak temperatures at the limit decreased substantially for mixtures with fuel/oxygen ratios even slightly rich of stoichiometric due to a transition from $\mathrm{O}(\mathrm{s})$ to $\mathrm{CO}(\mathrm{s})$ surface coverage. $\mathrm{CO}(\mathrm{s})$ is far less effective than $\mathrm{O}(\mathrm{s})$ at suppressing $\mathrm{CH}_{4}$ adsorption. Experiments in a heat-recirculating "Swiss roll" burner at low Reynolds number suggest that the fuel/oxygen ratio effect is commonplace in catalytic combustors near extinction. No corresponding behavior was found for non-catalytic combustion. While the use of supplemental $\mathrm{N}_{2}$ is not practical in microcombustors, combustion of slightly rich mixtures diluted with their own combustion products may achieve the same goal because it would probably prevent large $O(s)$ surface coverage just as $\mathrm{N}_{2}$ dilution does. These results suggest that near-stoichiometric mixtures and exhaust gas recirculation rather than lean mixtures are preferable for minimizing flame temperatures in catalytic micro-combustors. Precisely the same operating strategy is used (albeit for a completely different purpose) in automobiles having 3-way catalyst-based emissions reduction systems.

\section{Acknowledgements}

The authors would like to thank Prof. Takashi Niioka of Tohoku University for discussions on extinction characteristics of catalytic reactions. The USC portion of this work was supported by the DARPA Microsystems Technology Office, contract DABT63-99-C-0042.

\section{References}

1. Fu, K. et al., Proc. 2001 ASME International Mechanical Engineering Congress and Exposition (IMECE), New York.

2. Sitzki, L., et al., AIAA Paper 2001-1087 (2001).

3. Epstein, A.H., et al., International Symposium Transport Phenomena and Dynamics of Rotating Machinery (2000).

4. Lloyd, S.A., Weinberg, F.J., Nature 251:47-49 (1974). 
5. Hasegawa, T., Tanaka, R., Niioka, T., in Proceedings of the International Joint Power Generation Conference (Eds. Sanyal et al.), EC-Vol.5, Book No. G017072, ASME International, 1997, pp. 259-266.

6. Pfefferle, L.D., Pfefferle, W.C., Catal. Rev. Sci. Eng. 29:219-267 (1987).

7. Coltrin, M.E., Kee, R.J., Rupley, F.M., Int. J. Chem. Kinetics 23:1111-1128 (1991).

8. Warnatz, J., Allendorf, M.D., Kee, R.J., Coltrin, M.E., Combust. Flame 96:393-406 (1994).

9. Schaevitz, S.B., Franz, A.J., Jensen, K.F., Schmidt, M.A., $11^{\text {th }}$ International Conference on Solid-State Sensors and Actuators, Germany, 2001.

10. Zhang, C.B., Najafi, K., Bernal, L.P., Washabaugh, P.D., $11^{\text {th }}$ International Conference on Solid-State Sensors and Actuators, Germany, 2001.

11. Sitzki, L., et al., Third Asia-Pacific Conference on Combustion, Seoul, Korea, (2001), pp.473-476.

12. Maruta, K., et al., Third Asia-Pacific Conference on Combustion, Seoul, Korea, (2001), pp.219-222.

13. Raja, L.L., Kee, R.J., Deutschmann, O., Warnatz, J., Schmidt, L.D., Catal. Today 59:47-60 (2000).

14. Ohadi, M.M., Buckley, S.G., Experimental Thermal Fluid Sci. 25:207-217 (2001).

15. FLUENT 4.5.2, Fluent Inc., Lebanon, NH, 1998.

16. Deutschmann, O., Schmidt, L.D., AIChE J. 44: 2565 (1998)

17. Deutschmann, O., et al., Catal. Today 59:141-150 (2000).

18. Deutschmann, O., Schmidt, R., Behrendt, F., Warnatz, J., Proc. Comb. Inst. 26:1747-1754 (1996). 


\section{Figure Captions}

Figure 1. Equivalence ratio at the extinction limit of catalytic combustion as a function of the average mixture inlet velocity.

Figure 2. Heat release (top), heat loss (middle) and ratio of heat loss to heat generation (bottom) at the extinction limit conditions as a function of the averaged mixture inlet velocity.

Figure 3. Axial temperature profile of channel wall for cases $a, b$ and $c$ (see Fig. 1).

Figure 4. Profiles of $\mathrm{CH}_{4}$ mole fraction in the gas phase next to the channel wall and heat release profile along channel wall for cases $a$ (upper) and $b$ (lower)

Figure 5. Profiles of surface coverage for cases $a$ (upper) and $b$ (lower).

Figure 6. Extinction limit boundary of $\mathrm{N}_{2}$-diluted catalytic methane-oxygen mixtures for averaged inlet mixture velocity $0.06 \mathrm{~m} / \mathrm{s}$ and $\mathrm{H}=5 \mathrm{~W} / \mathrm{m}^{2}-\mathrm{K}$.

Figure 7. Surface coverage profiles of $\mathrm{N}_{2}$-diluted catalytic combustion for extinction limit fuel mole fractions at fuel/oxygen ratio $=0.5$ (top) and 0.52 (bottom)

Figure 8. Experimental values of minimum propane concentration in propane-oxygen-nitrogen mixtures supporting combustion in a 3-turn Swiss-roll inconel combustor as a function of equivalence ratio and corresponding maximum temperatures at these propane concentrations. 


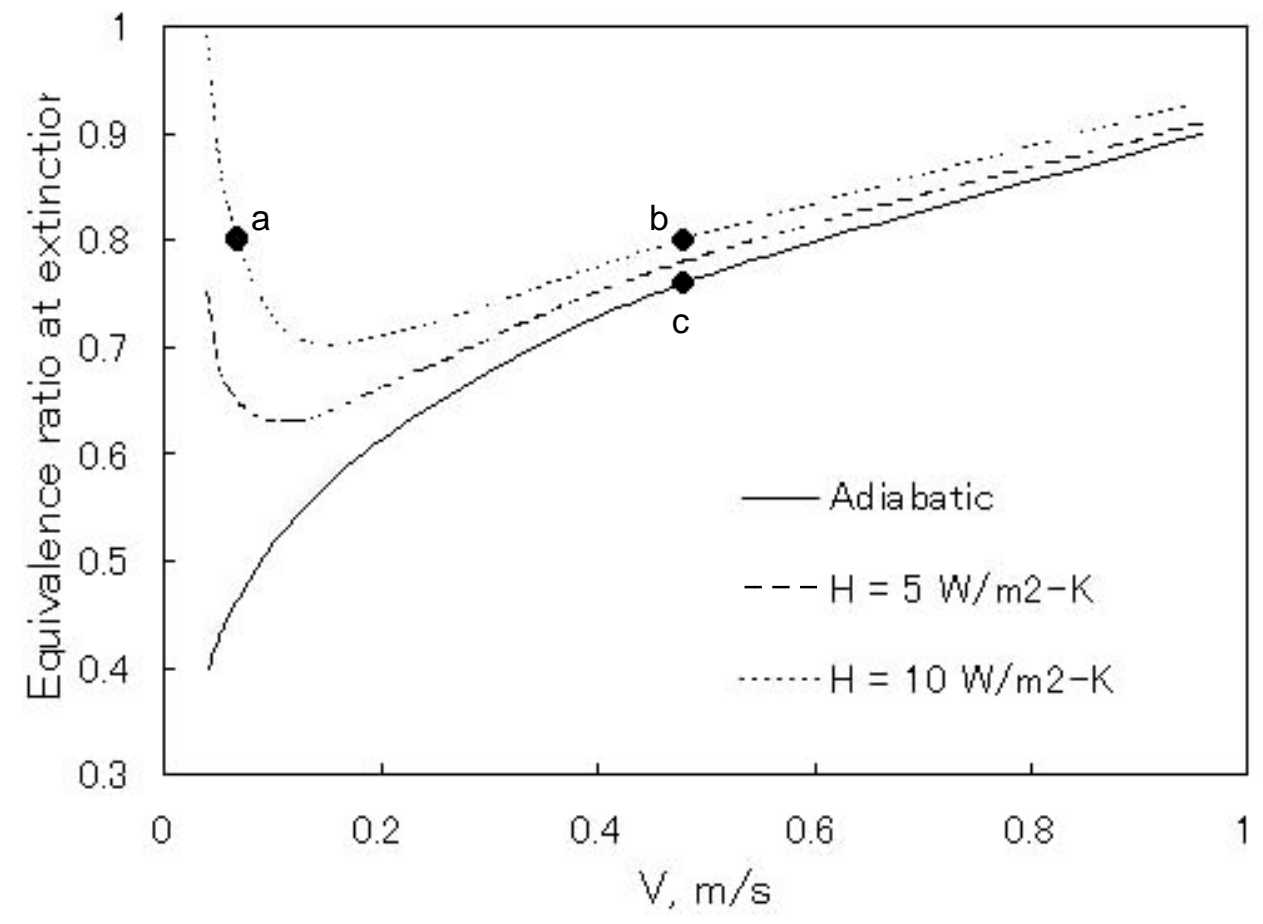

Figure 1. Equivalence ratio at the extinction limit of catalytic combustion as a function of the average mixture inlet velocity. 

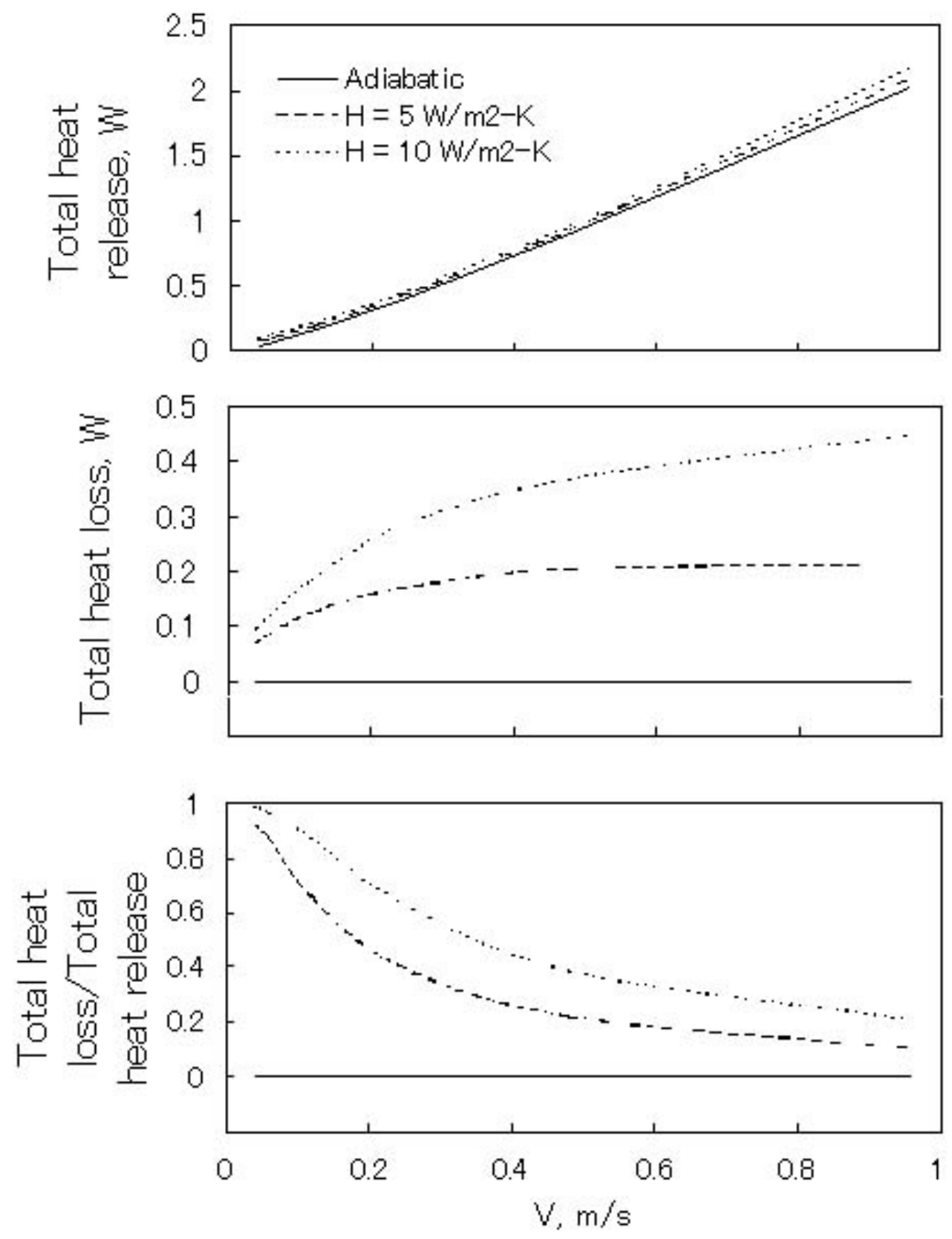

Figure 2. Heat release (top), heat loss (middle) and ratio of heat loss to heat generation (bottom) at the extinction limit conditions as a function of the averaged mixture inlet velocity. 


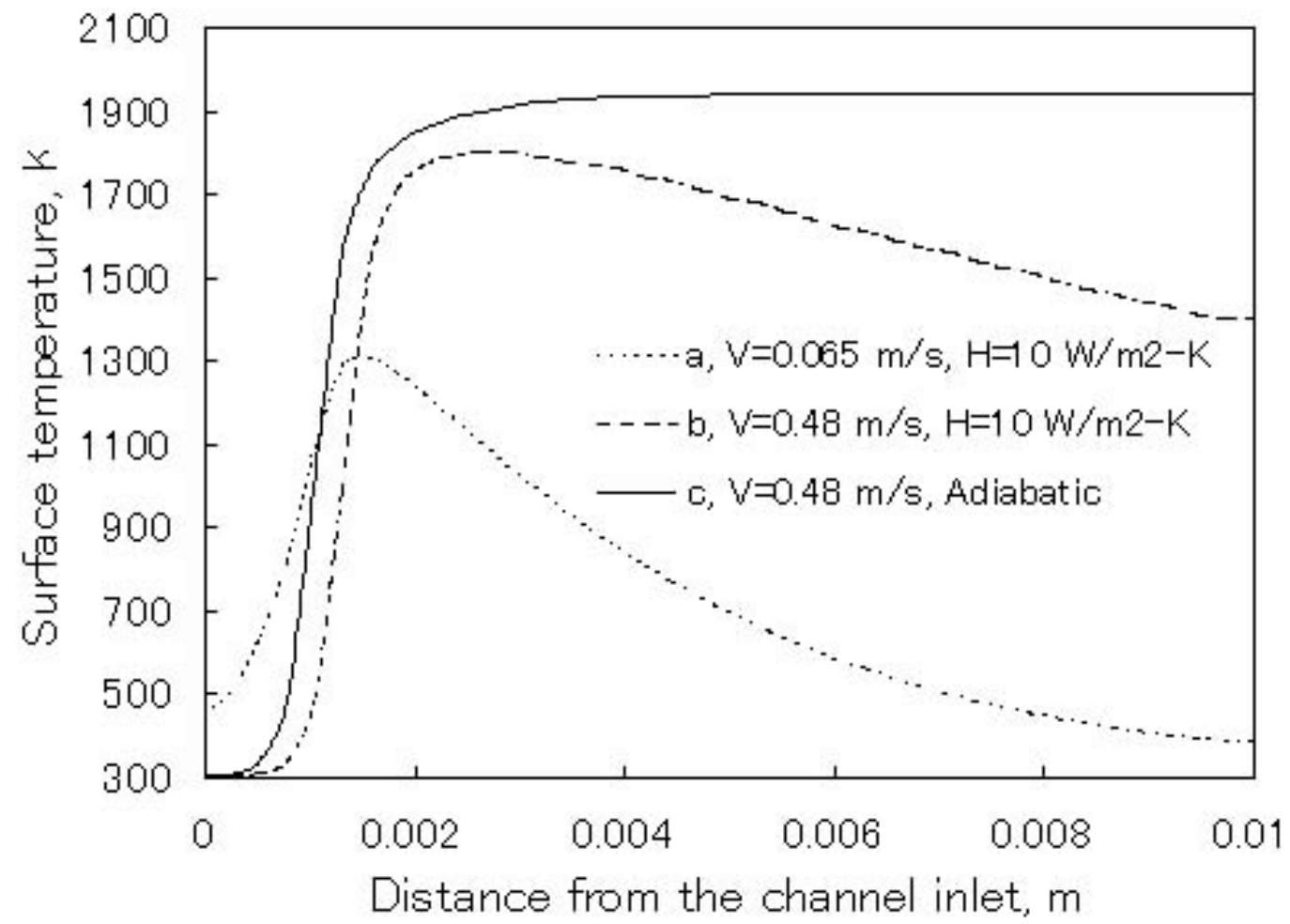

Figure 3. Axial temperature profile of channel wall for cases $a, b$, and $c$ (see Fig. 1) 

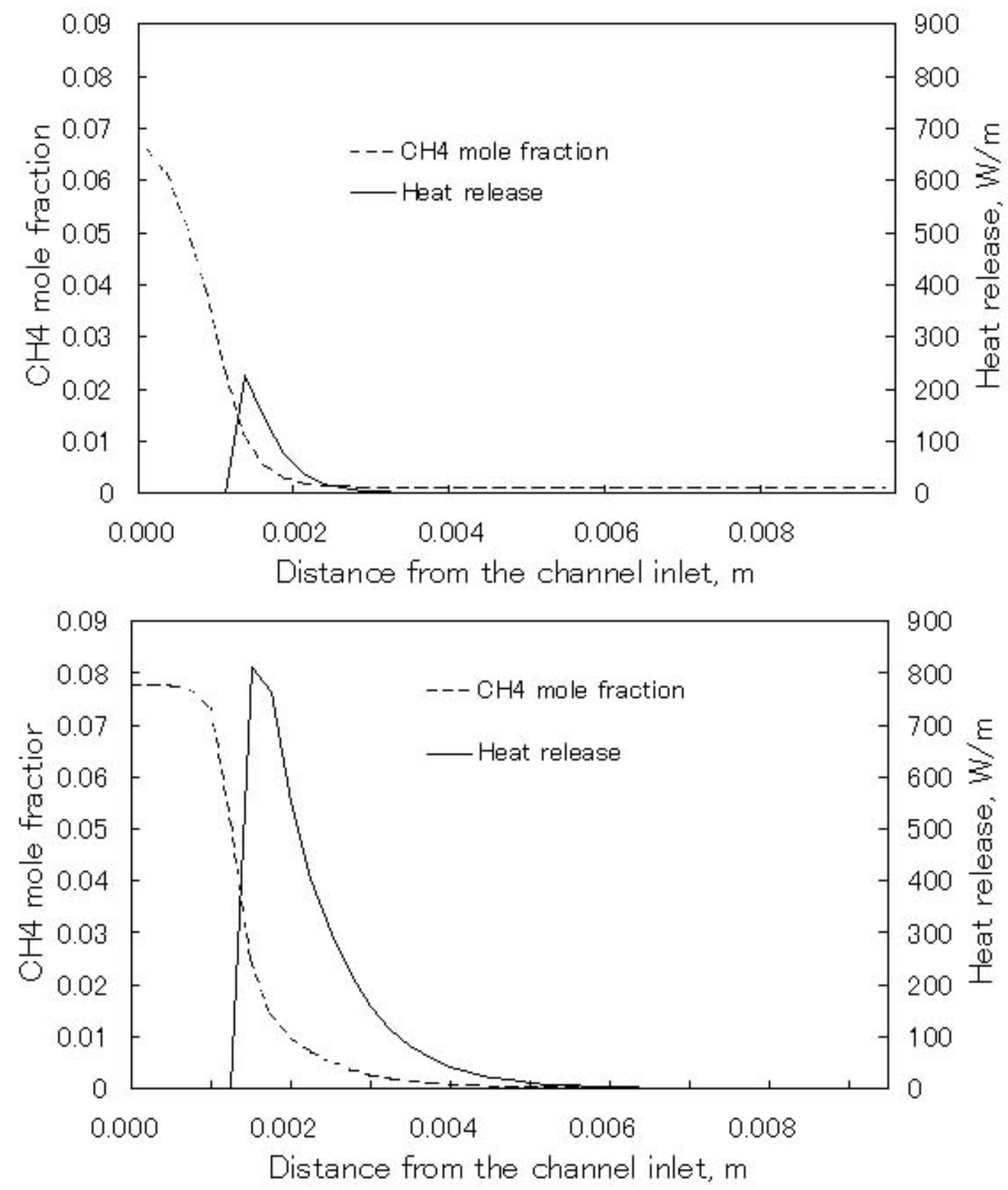

Figure 4. Profiles of $\mathrm{CH}_{4}$ mole fraction in the gas phase next to the channel wall and heat release profile along channel wall for cases $a$ (upper) and $b$ (lower) 

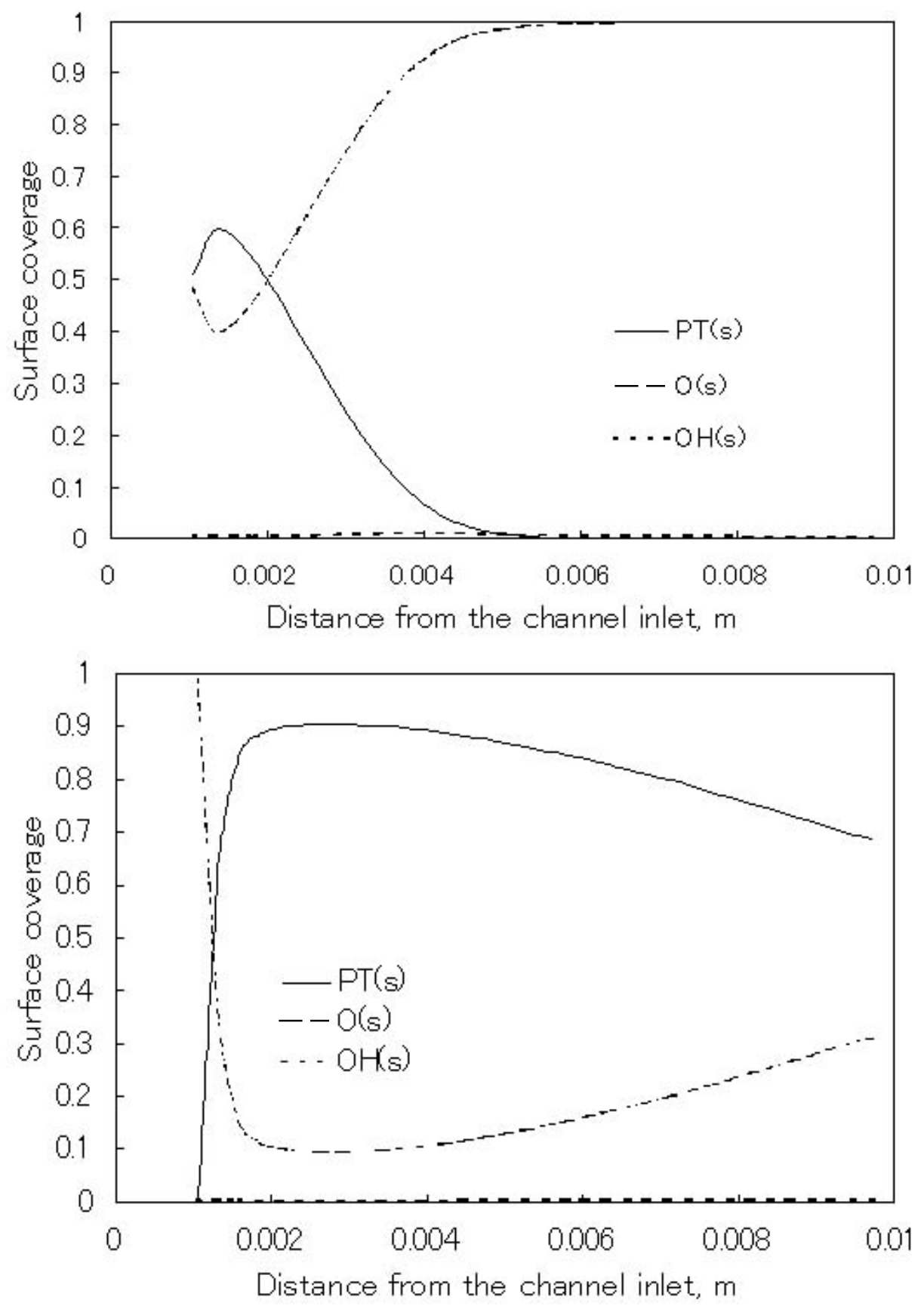

Figure 5. Profiles of surface coverage for cases $a$ (upper) and $b$ (lower). 


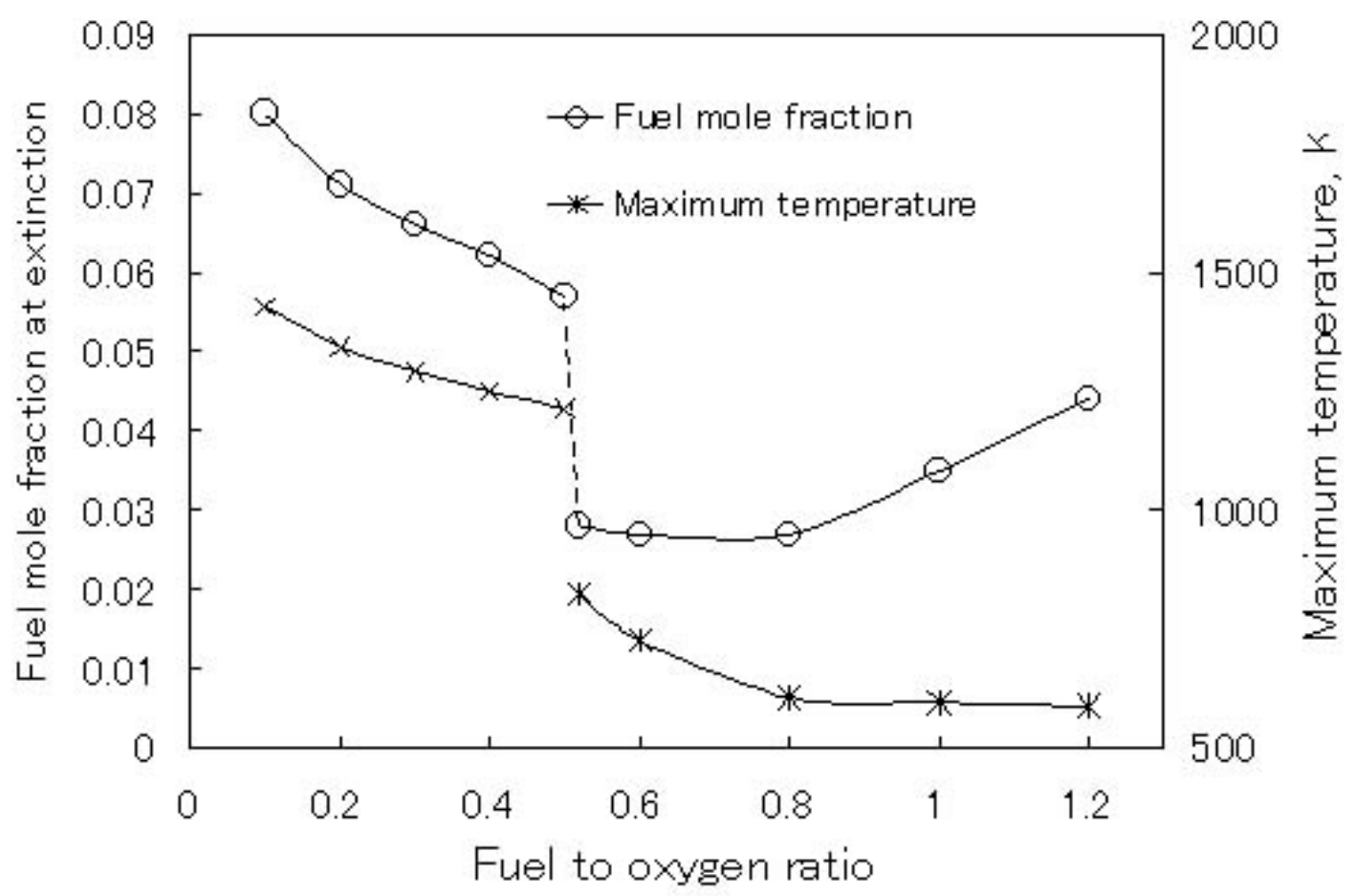

Figure 6. Extinction limit boundary of $\mathrm{N}_{2}$-diluted catalytic methane-oxygen mixtures for averaged inlet mixture velocity $0.06 \mathrm{~m} / \mathrm{s}$ and $\mathrm{H}=5 \mathrm{~W} / \mathrm{m}^{2}-\mathrm{K}$. 

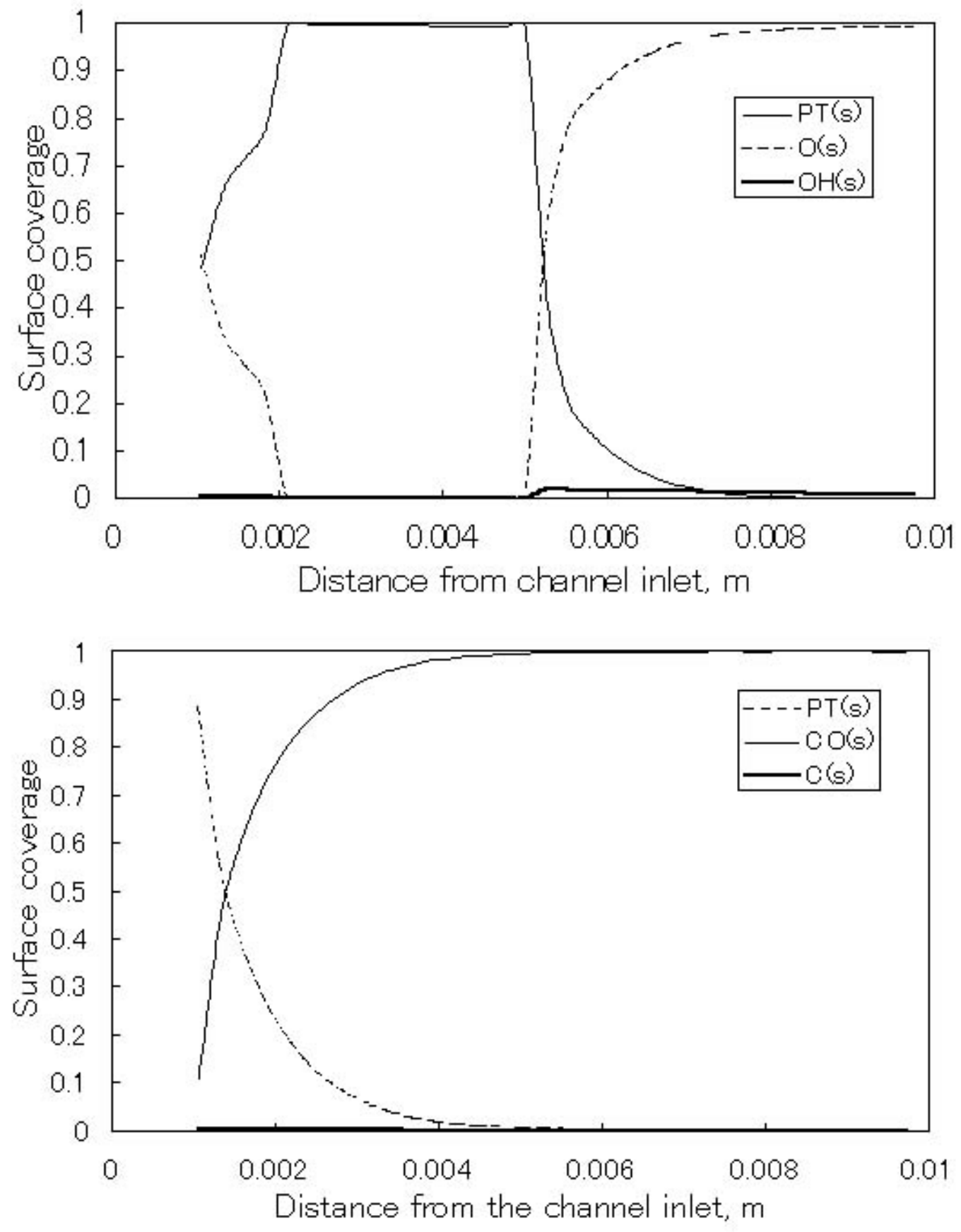

Figure 7. Surface coverage profiles of $\mathrm{N}_{2}$-diluted catalytic combustion for extinction limit fuel mole fractions at fuel/oxygen ratio $=0.5$ (top) and 0.52 (bottom) 


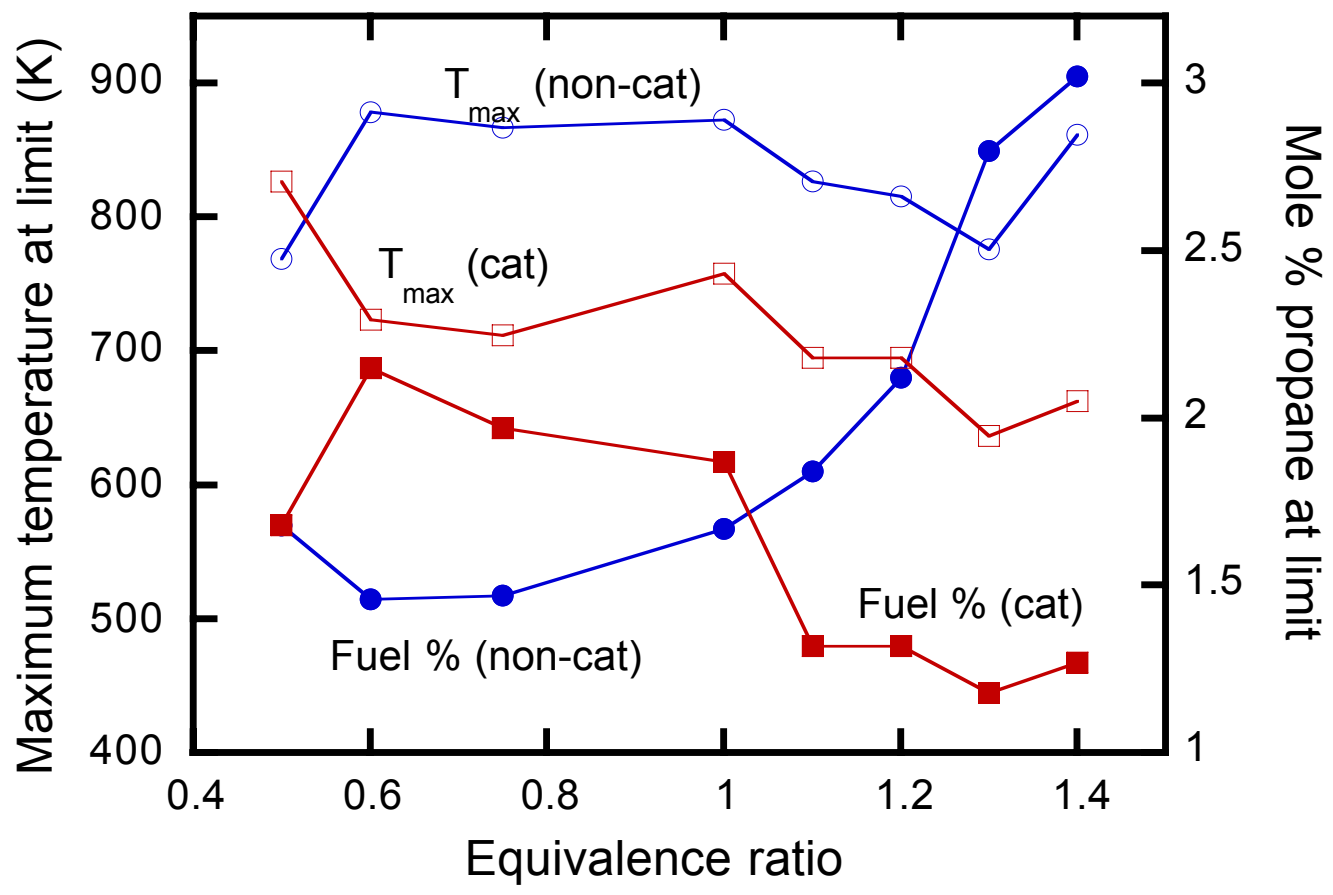

Figure 8. Experimental values of minimum propane concentration in propane-oxygen-nitrogen mixtures supporting combustion in a 3-turn Swiss-roll inconel combustor as a function of equivalence ratio and corresponding maximum temperatures at these propane concentrations. 